\title{
ADAPTIVE STRUCTURES - SOFT MECHANICAL APPROACH
}

\author{
M.C. PHOCAS AND K.C. ALEXANDROU \\ Department of Architecture, University of Cyprus, Cyprus.
}

\begin{abstract}
Since their earliest conceptualization, structures with reconfigurable characteristics contributed to the emergence of an architecture, able to respond and adjust itself to shifting environmental conditions, or time dependent users' needs. In this respect, the development of tensegrity and scissor-like structures to obtain adaptive capabilities, is primarily based on articulated joints and embedded mechanical actuators, following a hard mechanical approach. Although these systems are usually designed to use a small number of components to achieve maximum shape adjustments, their implementation often causes an increase of unsustainable processes with regard to the number and characteristics of the actuators used and mechanisms complexity, as well as energy-inefficient processes, in terms of both construction and kinetic operation. An alternative soft approach for adaptive structures is proposed in the current paper through an implementation of hybrid cable bending-active members, while the latter replaces multiple local hinges through reversible elastic bending deformations. Through the cables own length modification, these are responsible for the structure deformability and sufficient prestressing of the primary elastic members. Such pliable structures increase the level of design complexity due to the inherent elastic properties of the materials used and their nonlinear structural behaviour during transformation. In demonstrating this, a series of single, coupled and coupled-interconnected cable bending-active system configurations are investigated. Results obtained describe the stress distribution between the structural components during the systems' form-finding process and load-bearing behaviour.

Keywords: adaptive structures, cable bending-active structures, finite-element analysis, form-finding, soft mechanical approach.
\end{abstract}

\section{INTRODUCTION}

The necessity for overcoming static, heavyweight and energy inefficient building components, triggered the conceptualization and the evolution of adaptive systems [1]. Chronologically, the development of kinetic structures, primarily in terms of deployable tensegrity and scissor-like systems has been influenced by architectural form requirements, aesthetic factors, structural optimisation criteria, performance capacity and economy [2, 3]. So far, such systems are mainly based on kinetic mechanisms followed by hard mechanical approaches, while taking into consideration aspects of self-weight minimisation, modularity, connectivity and constructability [4]. While both aforementioned systems do not provide extensive flexibility, since their motions are limited between a closed and open state, reconfigurable systems have been acknowledged for their enhanced adaptive behaviour in terms of their physical ability to reconfigure themselves in various modular geometries and overall morphologies [5]. In many cases, the use of embedded computation and actuators enables real-time kinetic adaptation and structural control, resulting in unique adaptive responses [6]. Although current developments and implemented examples that attain the above attributes have verified their ability to adapt and support adequate morphological alterations, these are often characterized as complex and energy inefficient [7].

In extent, recent research activities focus on applications of soft, pliable materials, characterised by their passive elastic properties [8]. The alternative soft mechanical approach is based on implementation of elastically deformable members that may vary in shape and assemblage [9]. In principle, elastic deformation acting on primary elastic members can 
replace conventional catenary systems of multiple local hinges and linkages, with a single member. Planar bending-active members of relatively thin section prompt controllable elastic deformations, while they preserve geometrical reversibility, achieving in this way enhanced autonomy during different configurational transitions [10]. Compared to the section or vector-active structural systems, where stresses are stored inside the material to maintain their rigidity, form-active structures express the imposed loads visually through their deformation process, enabling simultaneously an increase of their stiffness. This approach can render the possibility to form single- or multi-curved geometries from straight or planar members, and can be proven very valuable to the design of adaptive structures, as it allows a wider spectrum of geometrical variations to emerge.

The design of lightweight adaptive structures using active deformation as a primary agent for the morphological transformation and structural capacity investigation, has been fairly characterised as an approach instead of an indicative system or action [11]. This designation has been selected, because of the form-finding process that takes place in the assembly stage. Originally, structures that have been constructed following the principles of this approach, have been investigated in their deformed shape using experimental physical models, or simply the designer's intuition [12]. Indicative example is the elastic gridshell of the Mannheim multihall designed by Frei Otto in 1973. The form-finding of the structure was investigated by using the hanging model technique [13]. Meanwhile form-finding processes can be numerically investigated with relatively high accuracy [14].

In the following sections six hybrid units composed of bending-active members and interconnecting cables are investigated in their form-found shapes and compared in terms of the component's inner stresses, and their load-bearing behaviour. The form-finding process of the bending-active members achieved through controlled shrinkage of the interconnecting cables is analytically presented on the basis of the simplest case, a single elastic member, and analysed for different thickness and width values of the member. The comparative analysis of the static behaviour of the units in their form-found state and under vertical loading is discussed in the last section of the paper.

\section{TYPOLOGICAL INVESTIGATION}

The design development and investigation of hybrid cable bending-active units is based on possible derivatives and more complex geometrical configurations of the simplest form of a two-component configuration, as shown in the case of Unit 1 in Fig. 1. The aim is to parametrically explore possible assemblies of multiple bending-active stripes, stabilised though main cable elements, which interconnect both ends of the primary members. Furthermore, secondary cables are only used as a simulation technique to enable primary members' fastening and unification of supports. In this respect, further unit compositions of two interconnected bending-active members may emerge, in order to enable observations on the morphological and structural capabilities of the systems as a result of the corresponding response of their components. In a preliminary stage, Unit 1 is parametrically examined using differentiated width and thickness values of the elastic member, in an attempt to decode the stress relations of the members. In a further stage, all units with constant elastic members' thickness of $10 \mathrm{~mm}$ and width of $240 \mathrm{~mm}$, are examined in their form-found state and compared in terms of their load-bearing behaviour under a uniformly distributed vertical load of $2.5 \mathrm{kN} / \mathrm{m}(\mathrm{Q})$.

All units are initially composed of planar primary bending-active members of variable thickness and width and reference undeformed span of $1 \mathrm{~m}$. The main cables connecting the elastic member ends have a diameter of $10 \mathrm{~mm}$. Unit 1 comprises the simplest form of a cable 


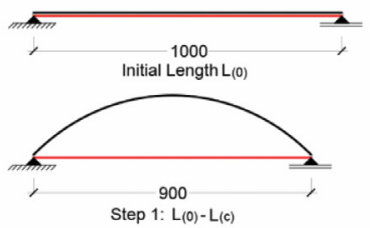

UNIT 1
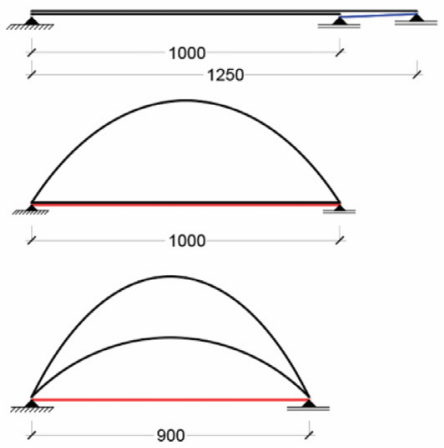

UNIT 3
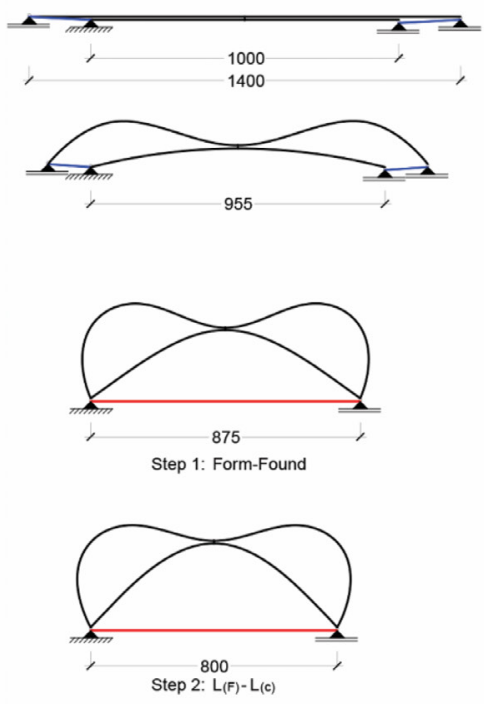

UNIT 5

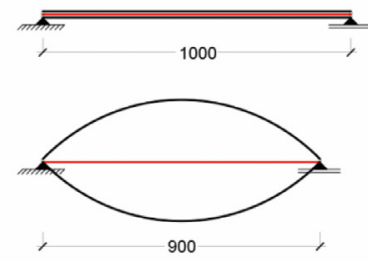

UNIT 2
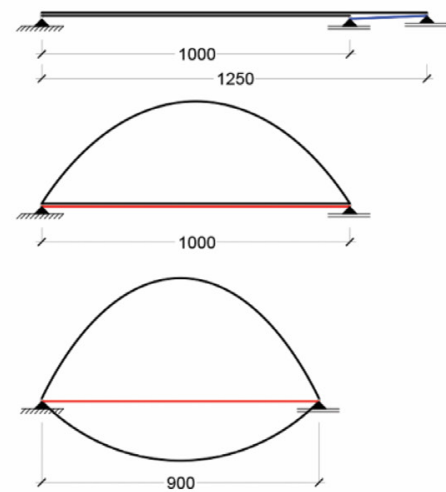

UNIT 4
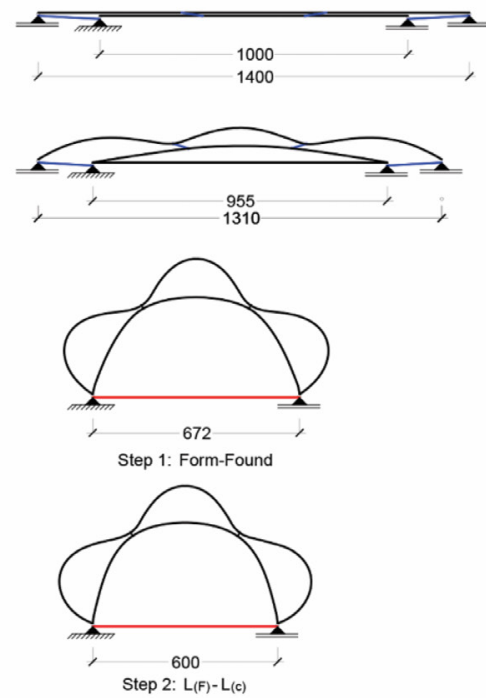

UNIT 6

Figure 1: Cable bending-active system configurations in planar and prestressing process.

bending-active system configuration, composed of a single elastic member connected at both ends through a cable. Unit 2 is based on the coupling of a bending-active members pair. Both members have the same initial length, but opposing transverse deformation direction. Through activation of the contracting cable, one member tends to bend upwards and the other, downwards. Unit 3 follows a coupled bending-active configuration with two bending-active 
members having differentiated length of 1.25 ratio. In a first stage, the outer member is forced to bend until it reaches the non-deformed length of the primary member, enabling at the same time the unification of the two end supports. This is achieved with a series of contracting cables that connect the sliding support nodes. In the subsequent stage the main cable that connects both bending-active members shrinks further until it reaches half of its initial length. Unit 4 is identical to Unit 3, but with inverted primary members' deformation. Unit 5 comprises an extension of Unit 2 configuration. An interconnection at the bending-active members' mid-point is assigned to provide an alternative form found shape. In Unit 6, the number of the members' interconnections is increased to two, placed symmetrically at one third of the members' length. Supplementary contracting cables are used to fasten the members together.

\subsection{Analysis model}

For the purpose of this study, a numerical investigation is followed using Finite-Element Analysis (FEA). In contrast to alternative form-finding calculation techniques, FEA takes into account the members' mechanical characteristics and in extent, non-linear effects that take place during the elastic deformations. The structural analysis software Sofistik has been used and in particular the alternative input tool provided by Sofistik, Teddy text editor, to support custom programming of the loadcase actions and regulation of the analysis preferences applied in each analysis step individually [15]. Fig. 2 demonstrates the workflow adopted for the static analysis of the units.

The proposed analysis model suggests the employment of initially, absolutely planar surfaces with regular mesh density of $40 \times 40 \mathrm{~mm}$ quadrilateral elements, assigned with elastic material properties (PTFE), i.e. elastic modulus of $2.5 \times 10^{6} \mathrm{GPA}$. The static analyses take into account both, material and geometrical nonlinear effects. These conditions are of major importance for the particular assembly processes and structural principles that characterize

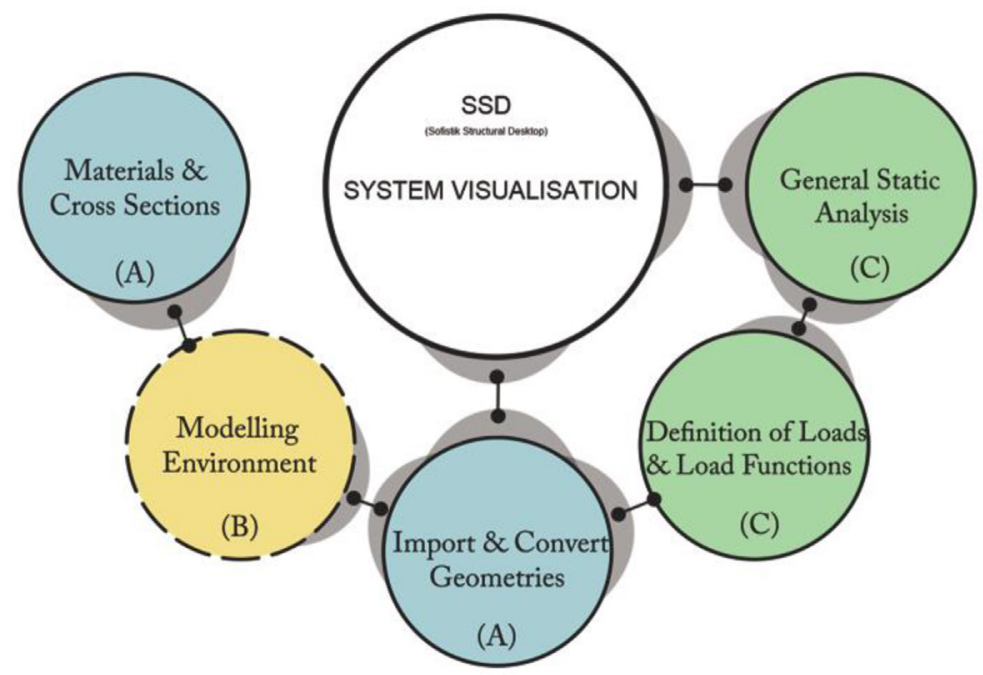

Figure 2: Finite element analysis workflow; blue: enabled in Sofistik graphical interface; yellow: enabled in third party modelling environment; green: enabled via text commands in Teddy. 
this approach. In this frame, the analysis model seeks to create sequential nonlinear analysis steps that follow in an analogous way the actual physical model assembly and subsequently the form-finding process of the system.

\subsection{Analysis stages}

The calculation of the deformations and the visualisation of the final configuration of the cable bending-active systems is divided into two indispensable stages, the prestressing stage of the bending-active members and the vertical load-bearing behaviour of the Units.

In the assembly stage, i.e. prestressing stage, the form-found geometry of the system is achieved and the necessary bending stresses are stored in the elastic members. The planar elements are bended to form curvilinear shapes, while these should simultaneously preserve the appropriate prestress for structural stability under respective applications. In complex Units configurations with multiple member constitutions of differentiated lengths, this process becomes even more complex and directly related to the sequence of assembly. In this respect, sequential deformation actions are followed for every member individually, Fig. 3. As a result, a set of multiple analyses are needed to take place, one after the other, until the overall structural composition is achieved. This stage is very critical and it necessitates the formulation of a modelling and execution strategy before reaching the final analysis step.

For the cases of Units 1 and 2 the deformed system configurations are realized through different cable shrinkage values of $100 \mathrm{~mm}$ per step, reaching a total shrinkage value of $500 \mathrm{~mm}$ in step 5. The gradual cable's shrinkage is applied in order to capture the behaviour of the units' deformations during prestressing of the elastic members. Units 3 and 4 necessitate

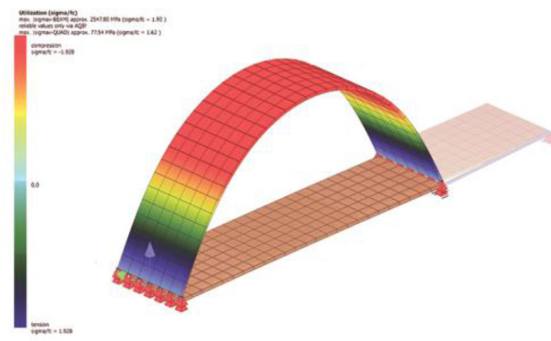

(a)

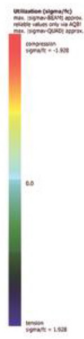

(c)
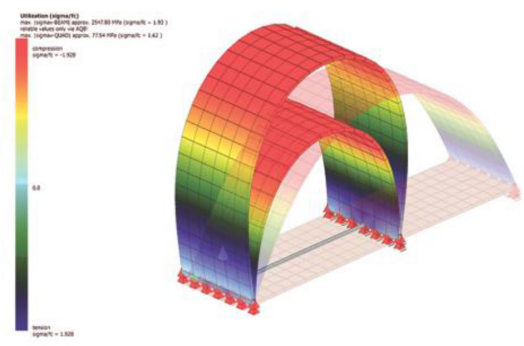

(b)

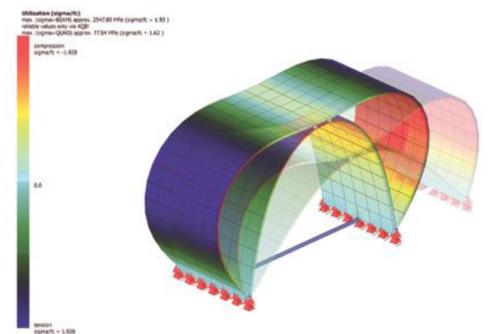

(d)

Figure 3: (a) Unit 3 assembly stage; secondary cables activation for bending-active members' support unification; (b) main cable activation; (c) Unit 5 assembly stage; secondary cables activation for bending-active members' support unification; (d) main cable activation. 
deformation of the outward bending-active member with higher length, preceding activation of the main cable member to shrink. This is achieved through supplementary contracting elements that connect the two bending-active member's fastening points. Due to interconnection fastening, Units 5 and 6 acquire configurations that allow applying only four and two additional steps of the main cables' shrinkage, respectively, until the members reach half of their initial length.

Following prestressing of the bending-active members, static analysis is performed with regard to the units' load-bearing behaviour under vertical loading. Residual stresses that are generated from the deformation of the bending-active members at the assembly stage are of increased importance, and should be taken into consideration before proceeding with the vertical loading stage. The energy embedded in the bending-active members, causes noticeable effects on the stiffness of the systems, and it essentially defines the behaviour of the units under exogenous forces.

\section{STRUCTURAL RESPONSES}

Unit 1, representable of the simplest system configuration, has been parametrically investigated for different thickness and width values of the bending-active member, in order to analytically examine both components' behaviour in relation to the embedded stresses in the primary member. The unit responses are investigated in the form-finding stage with cable shrinkage levels of $100 \mathrm{~mm}$ in each step. The unit's target deformation, corresponding to half of the initial main cable's length, constitutes the final step of the assembly stage, yielding in total five cable's shrinkage steps. The results obtained refer to force interdependencies between the two components, deformations in relation to inner stresses of the member and the unit's response under vertical loading, Table 1 . The remaining five cable bending-active Units' configurations are presented in the final step of the assembly stage, as well as their load-bearing behaviour, only for a constant elastic members' thickness and width of 10 and $240 \mathrm{~mm}$, respectively, Table 2 .

According to the analysis results obtained in the assembly stage for Unit 1 , the tension force magnitude developed in the cable is primarily influenced by the elastic member's thickness. Modification of the bending-active member's thickness from 5 to $25 \mathrm{~mm}$ with constant width of $240 \mathrm{~mm}$, yields up to the final analysis step of the assembly stage, respective relative increases by 702, 237, 137 and $95 \%$ of the tension force developed in the cable. On the other hand, the bending-active member's width modification from 80 to $360 \mathrm{~mm}$ with constant thickness of $10 \mathrm{~mm}$, yields cable force relative increases by $100 \%$. The maximum cable's axial force in the case of maximum bending-active member's thickness of $25 \mathrm{~mm}$ and $240 \mathrm{~mm}$ width amounts $10.28 \mathrm{kN}$, whereas in the case of maximum member's thickness of $10 \mathrm{~mm}$ and $360 \mathrm{~mm}$ width, the cable's axial force amounts $0.88 \mathrm{kN}$. In all analysis steps with variable member's thickness and width, the bending-active member's deformation is practically proportional to the cable's axial force. All system configurations in any two subsequent steps yield an approximate increase of the cable's axial force by on average $7 \%$.

The bending moments of the elastic member increase with increasing member's deformation. In all cases, the absolute maximum bending moment in the member has 40, 30, 22 and $18 \%$ relative increase according to the cable shrinkage steps of $100 \mathrm{~mm}$. A bending-active member's thickness variation amplifies the bending moment by $677,237,137$ and $95 \%$ up to the final analysis step. The width modification of the bending-active member has practically no influence on the bending moments. An absolute maximum value of the tension force of the elastic member of $42.68 \mathrm{kN} / \mathrm{m}$ is developed in step 4, for a member's thickness of $25 \mathrm{~mm}$ and 
Table 1: Single cable bending-active system configuration absolute responses.

\begin{tabular}{|c|c|c|c|c|c|c|c|}
\hline UNIT 1 & Step & $\begin{array}{c}\mathrm{U}(\mathrm{z}) \\
{[\mathrm{mm}]}\end{array}$ & $\begin{array}{c}\text { MYY } \\
{[\mathrm{kNm} / \mathrm{m}]}\end{array}$ & $\begin{array}{c}\mathrm{VYY} \\
{[\mathrm{kN} / \mathrm{m}]}\end{array}$ & $\begin{array}{c}\mathrm{NYY} \\
{[\mathrm{kN} / \mathrm{m}]}\end{array}$ & $\begin{array}{c}\text { NYY } \\
{[\mathrm{kN} / \mathrm{m}]}\end{array}$ & $\begin{array}{l}\text { Cable } \\
{[\mathrm{KN}]}\end{array}$ \\
\hline \multirow{6}{*}{$\begin{array}{l}\text { Thickness: } 5 \text { mm } \\
\text { [Width: } 240 \mathrm{~mm} \text { ] }\end{array}$} & 1 & 195 & 0.05 & 0.16 & 0.14 & 0.85 & 0.063 \\
\hline & 2 & 266 & 0.07 & 0.23 & 0.31 & 1.05 & 0.068 \\
\hline & 3 & 314 & 0.09 & 0.27 & 0.52 & 1.39 & 0.072 \\
\hline & 4 & 348 & 0.11 & 0.32 & 0.78 & 1.96 & 0.077 \\
\hline & 5 & 373 & 0.13 & 0.35 & 1.03 & 2.06 & 0.082 \\
\hline & Q & 367 & 0.13 & 0.58 & 1.44 & 3.60 & 0.310 \\
\hline \multirow{6}{*}{$\begin{array}{l}\text { Thickness: } 10 \text { mm } \\
\text { [Width: } 240 \mathrm{~mm} \text { ] }\end{array}$} & 1 & 195 & 0.41 & 1.29 & 1.05 & 24.85 & 0.500 \\
\hline & 2 & 266 & 0.59 & 1.83 & 2.13 & 36.07 & 0.540 \\
\hline & 3 & 314 & 0.74 & 2.26 & 3.20 & 45.27 & 0.574 \\
\hline & 4 & 348 & 0.88 & 2.64 & 4.74 & 53.62 & 0.613 \\
\hline & 5 & 373 & 1.01 & 2.96 & 3.85 & 51.59 & 0.658 \\
\hline & Q & 367 & 0.94 & 3.82 & - & 57.01 & 0.873 \\
\hline \multirow{6}{*}{$\begin{array}{l}\text { Thickness: } 15 \text { mm } \\
\text { [Width: } 240 \mathrm{~mm} \text { ] }\end{array}$} & 1 & 195 & 1.37 & 4.44 & 3.25 & 22.27 & 1.710 \\
\hline & 2 & 266 & 2.00 & 6.38 & 6.13 & 25.91 & 1.820 \\
\hline & 3 & 314 & 2.51 & 7.98 & 9.20 & 29.04 & 1.940 \\
\hline & 4 & 348 & 2.97 & 9.49 & 12.69 & 28.37 & 2.070 \\
\hline & 5 & 373 & 3.41 & 10.75 & 8.73 & 15.56 & 2.220 \\
\hline & Q & 367 & 3.35 & 11.57 & 3.62 & 20.04 & 2.440 \\
\hline \multirow{6}{*}{$\begin{array}{l}\text { Thickness: } 20 \text { mm } \\
\text { [Width: } 240 \mathrm{~mm} \text { ] }\end{array}$} & 1 & 195 & 3.26 & 10.90 & 7.14 & 52.12 & 4.050 \\
\hline & 2 & 266 & 4.74 & 15.84 & 12.78 & 59.23 & 4.320 \\
\hline & 3 & 314 & 5.95 & 20.09 & 19.97 & 62.83 & 4.590 \\
\hline & 4 & 348 & 7.04 & 24.20 & 25.24 & 57.03 & 4.900 \\
\hline & 5 & 373 & 8.09 & 27.63 & 15.22 & 29.40 & 5.270 \\
\hline & Q & 367 & 8.03 & 28.54 & 10.14 & 34.00 & 5.490 \\
\hline \multirow{6}{*}{$\begin{array}{l}\text { Thickness: } \mathbf{2 5} \mathbf{~ m m} \\
\text { [Width: } 240 \mathrm{~mm} \text { ] }\end{array}$} & 1 & 195 & 6.35 & 22.09 & 12.85 & 100.47 & 7.910 \\
\hline & 2 & 266 & 9.24 & 32.48 & 21.39 & 108.40 & 8.420 \\
\hline & 3 & 314 & 11.60 & 41.75 & 35.77 & 110.73 & 8.960 \\
\hline & 4 & 348 & 13.74 & 50.78 & 42.68 & 95.15 & 9.570 \\
\hline & 5 & 373 & 15.78 & 58.15 & 24.10 & 44.51 & 10.280 \\
\hline & Q & 367 & 15.72 & 59.20 & 19.04 & 49.16 & 10.500 \\
\hline \multirow{6}{*}{$\begin{array}{l}\text { [Thickness: } 10 \mathrm{~mm} \text { ] } \\
\text { Width: } \mathbf{8 0} \mathbf{~ m m}\end{array}$} & 1 & 195 & 0.41 & 1.26 & - & 2.10 & 0.169 \\
\hline & 2 & 266 & 0.59 & 1.78 & - & 2.23 & 0.180 \\
\hline & 3 & 314 & 0.74 & 2.17 & - & 2.37 & 0.191 \\
\hline & 4 & 348 & 0.88 & 2.48 & - & 2.52 & 0.205 \\
\hline & 5 & 373 & 1.01 & 2.74 & 0.08 & 2.69 & 0.220 \\
\hline & Q & 367 & 0.94 & 3.51 & - & 5.40 & 0.291 \\
\hline
\end{tabular}


Table 1: Continued

\begin{tabular}{lccccccc}
\hline & & $\begin{array}{c}\mathrm{U}(\mathrm{z}) \\
{[\mathrm{mm}]}\end{array}$ & $\begin{array}{c}\text { MYY } \\
{[\mathrm{kNm} / \mathrm{m}]}\end{array}$ & $\begin{array}{c}\text { VYY } \\
{[\mathrm{kN} / \mathrm{m}]}\end{array}$ & $\begin{array}{c}\text { NYY } \\
{[\mathrm{kN} / \mathrm{m}]}\end{array}$ & $\begin{array}{c}\text { NYY } \\
{[\mathrm{kN} / \mathrm{m}]}\end{array}$ & $\begin{array}{c}\text { Cable } \\
{[\mathrm{KN}]}\end{array}$ \\
\hline [Thickness: 10 mm] & 1 & 195 & 0.41 & 1.27 & 0.83 & 4.28 & 0.338 \\
Width: 160 mm & 2 & 266 & 0.59 & 1.80 & 1.89 & 4.80 & 0.360 \\
& 3 & 314 & 0.74 & 2.20 & 3.08 & 5.47 & 0.383 \\
& 4 & 348 & 0.88 & 2.54 & 3.87 & 5.84 & 0.409 \\
& 5 & 373 & 1.01 & 5.82 & 2.66 & 4.40 & 0.439 \\
& $\mathrm{Q}$ & 364 & 0.90 & 3.86 & - & 6.81 & 0.603 \\
[Thickness: $10 \mathrm{~mm}]$ & 1 & 195 & 0.41 & 1.31 & 1.22 & 9.12 & 0.675 \\
Width: 320 mm & 2 & 266 & 0.59 & 1.87 & 2.25 & 11.27 & 0.719 \\
& 3 & 314 & 0.74 & 2.32 & 3.32 & 14.22 & 0.765 \\
& 4 & 348 & 0.88 & 2.76 & 5.35 & 16.16 & 0.817 \\
& 5 & 373 & 1.01 & 3.14 & 5.17 & 10.71 & 0.877 \\
& $\mathrm{Q}$ & 369 & 0.96 & 3.61 & 3.23 & 11.13 & 1.026 \\
\hline
\end{tabular}

Table 2: Cable bending-active system configurations' responses with elastic members' sectional dimensions of $10 / 240 \mathrm{~mm}$.

\begin{tabular}{lccccccc}
\hline & & & MYY & $\begin{array}{c}\text { VYY } \\
{[\mathrm{kN} / \mathrm{m}]}\end{array}$ & $\begin{array}{c}\mathrm{NYY} \\
{[\mathrm{kN} / \mathrm{m}]}\end{array}$ & $\begin{array}{c}\mathrm{NYY} \\
{[\mathrm{kN} / \mathrm{m}]}\end{array}$ & Cable $[\mathrm{KN}]$ \\
\hline Unit 1 & 5 & 373 & 1.01 & 2.96 & 3.85 & 51.59 & 0.658 \\
& $\mathrm{Q}$ & 367 & 0.94 & 3.82 & - & 57.01 & 0.873 \\
Unit 2 & 5 & 373 & 1.01 & 2.96 & 3.85 & 51.59 & 1.316 \\
& $\mathrm{Q}$ & 367 & 0.94 & 3.82 & - & 57.01 & 1.746 \\
Unit 3 & 5 & 567 & 1.01 & 4.92 & 22.65 & 19.39 & 1.026 \\
& $\mathrm{Q}$ & 547 & 0.74 & 4.81 & 22.44 & 19.82 & 1.116 \\
Unit 4 & 5 & 567 & 1.01 & 4.92 & 22.65 & 19.39 & 1.026 \\
& $\mathrm{Q}$ & 547 & 0.74 & 4.81 & 22.44 & 19.82 & 1.116 \\
Unit 5 & 4 & 386 & 1.28 & 5.45 & 6.00 & 5.78 & 0.724 \\
& $\mathrm{Q}$ & 376 & 1.25 & 6.83 & 4.17 & 7.09 & 0.871 \\
Unit 6 & 2 & 451 & 1.83 & 14.59 & 17.25 & 16.67 & 0.861 \\
& $\mathrm{Q}$ & 449 & 1.83 & 14.67 & 17.69 & 15.99 & 0.195 \\
\hline
\end{tabular}

width, $240 \mathrm{~mm}$. Similarly, an absolute maximum compression force of $110.73 \mathrm{kN} / \mathrm{m}$ is developed in step 3, for the same member's section. Considering the member's width variation, a maximum respective value of $16.16 \mathrm{kN} / \mathrm{m}$ is traced in step 4 , for a member's thickness of $10 \mathrm{~mm}$ and width, $320 \mathrm{~mm}$. The shear force exhibits a linear response with regard to the deformations, and reaches an absolute maximum value of $58.15 \mathrm{kN} / \mathrm{m}$ in step 5 , for the case of maximum member's thickness of $25 \mathrm{~mm}$ and width, $240 \mathrm{~mm}$. Fig. 4 captures the deformed shape of Unit 1 for all five steps of the cable shrinkage throughout the assembly stage. 


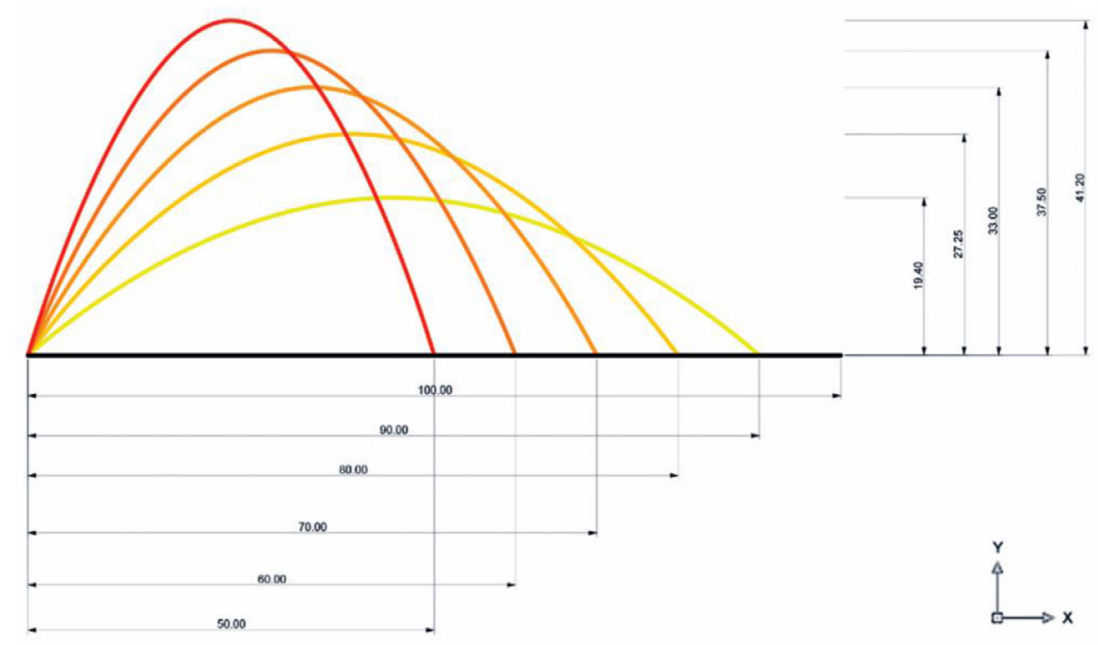

Figure 4: Unit 1; 5 steps of $100 \mathrm{~mm}$ cable axial shrinkage each in assembly stage.

In the vertical loading stage, the maximum cable force increases non-exponentially with increasing elastic member's thickness. For a member's thickness of up to $25 \mathrm{~mm}$ and width, $240 \mathrm{~mm}$, the maximum cable force has relative increases by $182,179,125$ and $91 \%$, respectively. The respective increase ratios for each elastic member's thickness case compared to the respective final step of the prestressing stage amount 278, 32, 9, 4 and 2\%. Furthermore, in this stage both the elastic member's bending moment and shear force decrease slightly. For a member's thickness of $25 \mathrm{~mm}$ and width, $240 \mathrm{~mm}$, the maximum compression force of the elastic member increases by $10 \%$, compared to the final step of the prestressing stage, whereas the maximum tension force decreases by $21 \%$, respectively. When the elastic member's thickness is below $15 \mathrm{~mm}$, then the tension force is negligible. A maximum deformation at mid-span, of $0.6 \mathrm{~cm}$, is derived in the case of a bending-active member's thickness of $5 \mathrm{~mm}$ and width, $240 \mathrm{~mm}$.

A comparison of the analysis results for all six units in their form-found state is shown in Table 2. A maximum cable force of $1.316 \mathrm{kN}$ is developed in Unit 2, which is two times higher than the respective lowest value developed in Unit 1 . A maximum bending moment of $1.83 \mathrm{KNm} / \mathrm{m}$ is developed in Unit 6 , since its deformed curvature reaches a higher level compared to all other system configurations. Axial forces developed in the elastic members vary the most between different configurations. An absolute maximum value of $51.59 \mathrm{kN} / \mathrm{m}$ is developed in Unit 1 and a minimum value of $5.78 \mathrm{kN} / \mathrm{m}$, in Unit 5 .

In the vertical loading stage of all system configurations, as included in Table 2, there exists a high fluctuation between 2.0 to $0.2 \mathrm{~cm}$ in the deformation results at mid-span of the Units 3 and 4 and the Unit 6, respectively. In all cases, compared to the final step of the prestressing stage, in Units 1 and 2, 3 and 4, and 5, the cable forces increase by 32, 8 and 20\%, respectively; in Unit 6 the respective maximum value decreases by $77 \%$. The elastic members' bending moments decrease slightly, due to the member's reverse deformations. Furthermore, the absolute maximum axial forces developed in the elastic members under vertical loading, increase only in Units 1, 2, 5 and 6. 


\section{CONCLUSIONS}

A series of adaptive unit structures has been introduced in the current paper. The structures are composed of bending-active members and interconnecting cables following a soft mechanical approach in achieving adaptiveness with regard to their configuration state and deformation control under external loading. In particular, the numerical investigation conducted refers to six units of single, coupled and coupled-interconnected cable bending-active configurations. The results obtained through the Finite-Element analysis conducted, describe the stress distribution between the structural components during the systems' form-finding process and the systems' load-bearing behavior under vertical loading. It has been demonstrated that the interconnecting cables own shrinkage induces deformation control and prestressing of the primary elastic members. The maximum cable forces developed are primarily influenced by the elastic members' thickness. These are proportional to the bending moments of the elastic members and their induced deformations. Under vertical loading the maximum cable forces increase further and the bending moments of the elastic members decrease slightly. Furthermore, a direct comparison of the individual system configurations behaviour is not self-evident due to the prevailing nonlinearities of the system responses.

\section{REFERENCES}

[1] Schnädelbach, H., Adaptive architecture. A Conceptual Framework. Proceedings of Media City, Weimar, Germany, pp. 523-555, 2010.

[2] Engel, H., Structure Systems. Hatje Cantz: Stuttgart, 2009.

[3] Escrig, F., Emilio perez pinero: inventor of deployability. Structures and Architecture: Concepts, Application and Challenges, Proceedings of Second International Conference on Structures \& Architecture, ICSA2013, ed. P.J.S. Cruz, Guimaraes, pp. 42-57, 2013. http://dx.doi.org/10.1201/b15267-6

[4] Phocas, M.C., Kontovourkis, O. \& Nicolaou, N., Design concept of a kinetic formactive hybrid envelope structure. Design \& Nature and Ecodynamics, 9(1), pp. 13-30, 2014.

http://dx.doi.org/10.2495/DNE-V9-N1-13-30

[5] Elkhayat, Y.O., Interactive movement in kinetic architecture. Engineering Sciences, 42(2), pp. 816-845, 2014.

[6] Fox, M. \& Bryant, Y., Intelligent Kinetic Systems. Springer: Dublin, 1999.

[7] Khoo, C.K., Salim, F. \& Burry, J., Designing architectural morphing skins with elastic modular systems. Architectural Computing, 9(4), pp. 379-419, 2011. http://dx.doi.org/10.1260/1478-0771.9.4.397

[8] Hensel, M., Achim, M. \& Weinstock, M., Emergent Technologies and Design: Towards a Biological Paradigm for Architecture, Routledge: Oxford, 2013.

[9] Tamke, M., Lafuente Hernandez, E., Holden Del, A. \& Ramsgard Thomsen, M., A new material practice: integrating design and material behavior. Proceedings of the Symposium on Simulation for Architecture and Urban Design, SimAUD, Orlando, pp. 5-12, 2012.

[10] Phocas, M.C., Kontovourkis, O. \& Alexandrou, K., Design of a controlled cable bending-active structure. Proceedings of International Conference on Adaptation and Movement in Architecture, ICAMA 2013, eds. C. Ripley \& M. Asefi, Ryerson University: Toronto, pp. 237-249, 2013. 
[11] Lienhard, J., Bending-Active Structures: Form-Finding Strategies using Elastic Deformation in Static and Kinetic Systems and the Structural Potentials therein. Ph.D. Thesis, University of Stuttgart: Stuttgart, 2014.

[12] Otto, F., Spannweiten, Verlag Ullstein: West Berlin, 1965.

[13] Liddell, I., Frei otto and the development of gridshells. Case Studies in Structural Engineering, 4, pp. 39-49, 2015.

http://dx.doi.org/10.1016/j.csse.2015.08.001

[14] Veenendaal, D. \& Block, P., An overview and comparison of structural form-finding methods for general networks. Solids and Structures, 49(26), pp. 3741-3753, 2012. http://dx.doi.org/10.1016/j.ijsolstr.2012.08.008

[15] SOFISTIK, General Static Analysis of Finite Element Structures. Sofistik Manual, Version 2014-8. Sofistik AG: Oberschleissheim, 2014. 